\title{
Conjoined Stent Technique for Radiation Induced Long Segment Carotid Stenosis and Pseudoaneurysm
}

\author{
Atulabh Vajpayee, DM, Gourav Goyal, DM, Rama Kant, MD
}

Radiation induced carotid stenosis (RICS) is known but challenging complication of head and neck irradiation. Endovascular revascularization is preferred treatment modality than surgical revascularization. Sometimes endovascular treatment may be difficult in view of long segment of stenosis and associated pseudoaneurysm. We report a unique technique of carotid stenting named as "conjoined stent technique" in a challenging case of RICS with long segment of stenosis and pseudoaneurysm. In this technique we overlapped distal end of one stent with proximal end of second stent to occlude pseudoaneurysm. "Conjoined stent technique" may be viable option in case of long segment of RICS with associated pseudoaneurysm and alternative to flow diverters in extracranial carotid pseudoaneurysm.

Key Words : Radiation injuries; Pseudoaneurysm, carotid; Conjoined stent; Carotid stenosis/therapy

Radiation induced carotid artery stenosis (RICS) is a known complication of head and neck radiation therapy. Latency period of carotid stenosis following radiation is prolonged and sometimes it may be up to 20 years [1]. Underlying pathophysiology of carotid stenosis following radiation is thought to be accelerated atherosclerosis or panarteritis triggered by radiation $[2$, 3]. Surgical carotid endarterectomy is difficult and challenging in this situation because of associated scarring of vessel wall and tissue planes, involvement

All authors: Advanced Neurocare Institute, GBH American Hospital, Udaipur-Rajasthan, India

Received September 25, 2013; accepted after revision November 18, 2013.

Correspondence to: Atulabh Vajpeyee, DM, Consultant Interventional Neurologist, Advanced Neurocare Institute, GBH American Hospital, 101, Kothi Bagh, Bhatt Ji Ki Bari, Meera Girls College Road, Udaipur-313001, Rajasthan, India

Tel. 91.294.305.6000-228 Fax. 91.294252.6982

E-mail: atulabh@gbhamericanhospital.com

This is an Open Access article distributed under the terms of the Creative Commons Attribution Non-Commercial License (http://creativecommons.org/licenses/by-nc/3.0) which permits unrestricted non-commercial use, distribution, and reproduction in any medium, provided the original work is properly cited. of long segment, presence of both intracranial and extracranial stenosis and inadequate wound healing and closure following the procedure [4,5]. Carotid angioplasty and stenting is more appropriate and provide maximum benefit in surgically inappropriate and high risk patients such as RICS [6,7]. We report a case of radiation induced long segment carotid stenosis with pseudoaneurysm treated by conjoined stent technique. This case is unique on account of not only long segment of stenosis but also due to presence of symptomatic pseudoaneurysm.

\section{CASE REPORT}

A 70-year-old man had history of carcinoma larynx (Stage I) treated with conventional radiotherapy with the dose of 70 Gy in the year 2000. In March 2013, he presented with complaint of recurrent transient episodes of left upper limb weakness. He had six such episodes during last three months. Each episode lasted for 2-3 minutes and used to improve on its own. He also complained small swelling in neck in right submandibular area and transient weakness on left side 


\section{Conjoined Stent Technique}

on pressing neck swelling. He had hypertension since 2008. He was nonsmoker and nonalcoholic. He had no known drug allergy. On examination, his left carotid artery was nonpalpable and right carotid artery was less palpable. On auscultation, carotid bruit was present on right side. Neurological examination was normal. Other systemic examination did not reveal any significant abnormality. Magnetic resonance imaging of brain did not reveal acute or old infarcts. Carotid Doppler revealed occlusion of left common carotid artery and significant long segment stenosis of right common and internal carotid artery. Diagnostic cerebral angiography was done which revealed long segment stenosis of right internal carotid artery $(70 \mathrm{cms}$ in length and 80$90 \%$ stenosis) with a pseudoaneurysm measuring 5.06 $\times 3.59 \mathrm{~mm}$ (Fig. 1A). Left carotid angiogram revealed complete occlusion of left internal carotid artery. Left and right vertebral angiogram revealed good flow in vertebral and basilar arteries.

In view of long segment of stenosis, potential clot embolization from pseudoaneurysm and possible rupture of pseudoaneurysm in future, it was planned to cover the whole length of stenosis with stent and apposing distal end of first closed cell design stent (Absolute pro $8 \times 60 \mathrm{~mm}$; Abbott Vascular, Santa Clara, CA, USA) with proximal end of second stent (Acculink 6-8 $\times 40 \mathrm{~mm}$; Abbott Vascular, Santa Clara, CA, USA). This was thought to provide extra metal coverage to vessel wall and reducing blood flow inside pseudoaneurysm to promote thrombosis in the aneurysm sac in corollary to flow diverter. After deploying the stent we inflated the balloon up to $10 \mathrm{~atm}$ for 10 seconds in each stent (Fig. 1B). Post angioplasty right carotid angiogram revealed good flow across the
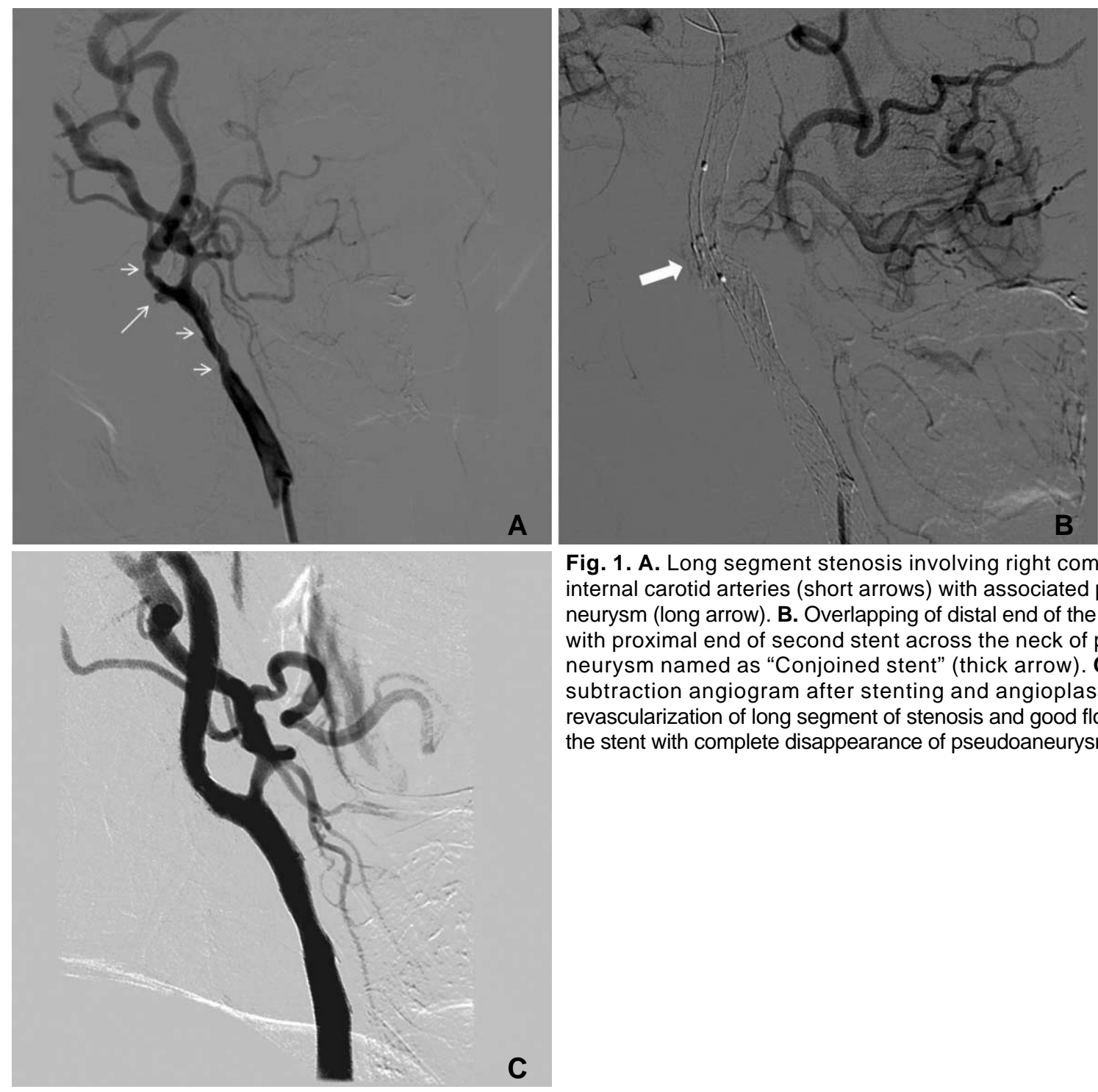

Fig. 1. A. Long segment stenosis involving right common and internal carotid arteries (short arrows) with associated pseudoaneurysm (long arrow). B. Overlapping of distal end of the first stent with proximal end of second stent across the neck of pseudoaneurysm named as "Conjoined stent" (thick arrow). C. Digital subtraction angiogram after stenting and angioplasty shows revascularization of long segment of stenosis and good flow across the stent with complete disappearance of pseudoaneurysm. 
stent with absent flow in pseudoaneurysm with complete circulation in right internal carotid artery territory (Fig. 1C).

On follow up at three months, patient was asymptomatic with no recurrence of episodes of transient weakness of left upper limb.

\section{DISCUSSION}

This case is different from reported cases of RICS. In this particular case, there were two challenges, first being long segment stenosis and second associated pseudo aneurysm. As panaretritis triggered by radiation makes the vessel susceptible for rupture, it is difficult to embolize associated pseudoaneurysm with coils. Long segment of carotid stenosis could not be stented with single stent. Conjoined stent technique helped in resolving both the issues. First, it provides adequate stent coverage of long segment of artery and second, overlapping the stent across the neck of pseudoaneurysm provides more metal coverage so as to reduce hemodynamic flow to pseudoaneurysm. Extra metal coverage will provide protection from filling of pseudoaneurysm and avoid migration of thrombus from pseudoaneurysm leading to thrombo-embolic complications.

Numbers of carotid complications have been reported following neck irradiation. Panarteritis, early artery occlusion within months and accelerated atherosclerosis are the common complications [2, 8]. Nasopharyngeal and laryngeal carcinomas usually lead to more frequent complications [9].

Angiographically, RICS is different from standard atherosclerotic carotid stenosis by presence of long segment stenosis and involvement of common carotid artery [10]. With improvement in technique and availability of self expandable stents, percutaneous revascularization is good alternative in RICS. Surgical treatment is more difficult in radiation induced stenosis compared to usual cases and may lead to more complications. Few reports are available on surgical treatment of radiation induced carotid stenosis [4, 5]. Carotid angioplasty and stenting of RICS has been reported to have very few complications [6, 7].

Recently, flow diverters have been used for the treatment of intracranial wide necked aneurysm or failed or difficult to coil aneurysms. Flow diverters are different from usual stent and provide 30-35\% metal coverage to the inner surface of target vessels with pore size of $0.02-0.05 \mathrm{~mm}[2,11]$. Placing a stent with high metallic coverage across the carotid bifurcation may hamper the blood supply of external carotid artery. Till now no flow diverter has been used in extra cranial carotid aneurysm. Conjoined stent technique provides extra metal coverage to vessel wall across the pseudoaneurysm and may be used as an alternative to flow diverters without compromising flow to external carotid artery particularly in extra cranial carotid stenosis.

This novel conjoined stent technique may be a viable option in future for such challenging cases. It requires more experience before considering it to be standard technique particularly in such cases.

\section{Acknowledgments}

We are acknowledging Mr. Chintan Joshi, chief technician for his help.

\section{References}

1. Elerding SC, Fernandez RN, Grotta JC, Lindberg RD, Causay LC, McMurtrey MJ. Carotid artery disease following external cervical irradiation. Ann Surg 1981;194:609-615

2. Fonkalsrud EW, Sanchez M, Zerubavel R, Mahoney A. Serial changes in arterial structure following radiation therapy. Surg Gynecol Obstet 1977;145:395-400

3. Atkinson JL, Sundt TM Jr, Dale AJ, Cascino TL, Nichols DA. Radiation-associated atheromatous disease of the cervical carotid artery: report of seven cases and review of the literature. Neurosurgery 1989;24:171-178

4. Rockman CB, Riles TS, Fisher FS, Adelman MA, Lamparello PJ. The surgical management of carotid artery stenosis in patients with previous neck irradiation. Am J Surg 1996;172:191-195

5. Kashyap VS, Moore WS, Quinones-Baldrich WJ. Carotid artery repair for radiation-associated atherosclerosis is a safe and durable procedure. J Vasc Surg 1999;29:90-96

6. Al-Mubarak N, Roubin GS, Iyer SS, Gomez CR, Liu MW, Vitek JJ. Carotid stenting for severe radiation-induced extracranial carotid artery occlusive disease. J Endovasc Ther 2000;7:36-40

7. Houdart E, Mounayer C, Chapot R, Saint-Maurice JP, Merland JJ. Carotid stenting for radiation-induced stenoses: a report of 7 cases. Stroke 2001;32:118-121

8. Murros KE, Toole JF. The effect of radiation on carotid arteries. A review article. Arch Neurol 1989;46:449-455

9. Cheng SW, Wu LL, Ting AC, Lau H, Lam LK, Wei WI. Irradiation-induced extracranial carotid stenosis in patients with head and neck malignancies. Am J Surg 1999;178:323-328

10. Cheng SW, Ting AC, Lam LK, Wei WI. Carotid stenosis after radiotherapy for nasopharyngeal carcinoma. Arch Otolaryngol Head Neck Surg 2000;126:517-521

11. Wong GK, Kwan MC, Ng RY, Yu SC, Poon WS. Flow diverters for treatment of intracranial aneurysms: current status and ongoing clinical trials. J Clin Neurosci 2011;18:737-740 